\title{
Chemotherapy with fumagillin and toltrazuril against kidney enlargement disease of goldfish caused by the myxosporean Hoferellus carassii.
}

\author{
Hiroshi Yokoyama*, Kazuo OgaWa* and Hisatsugu WaKabayashi* \\ *Department of Fisheries, Faculty of Agriculture, The University of Tokyo, \\ 1-1-1, Yayoi, Bunkyo-ku, Tokyo 113, Japan
}

(Received April 18, 1990)

\begin{abstract}
Chemotherapy with fumagillin (antibiotic) and toltrazuril (sym. triazinone) was tested against kidney enlargement disease (KED) of goldfish, caused by the myxosporean Hoferellus carassii. In October, goldfish naturally infected with an early stage of $H$. carassii were fed daily medicated diets of fumagillin or toltrazuril. After 1 month, fish treated with fumagillin- $0.1 \%$ or $1.0 \%$ diets never developed KED, and the prevalence of infection significantly decreased. In contrast, toltrazuril was not effective to KED. In November and January, fish with a gross sign of KED harbouring more advanced stages of $H$. carassii were also treated with fumagillin. Light and electromicroscopy revealed fumagillin caused fatal damages to developmental stages of $H$. carassii. Moreover, the infected epitherial cells were dead and fallen into the lumen, and only the basement membrane remained in the tubule after 1 to 2 weeks of treatment. Taking the seasonal development of the parasite into cosideration, an effective chemotherapy against KED is proposed.
\end{abstract}

Chemotherapy against myxosporean diseases has not been well established, but recently the antibiotic, fumagillin and the symmetrical triazinone, toltrazuril have been reported as efficacious drugs for several myxosporean infections.

Fumagillin, produced by the fungus, Aspergillus fumigatus, has long been known as a drug effective against microsporeans such as Nosema apis, a parasite of honey bees (KATZNELSON and JAMIESON, 1952; BAILY, 1953). In fish infecting microsporeans, KANO et al. (1982) studied "Beko" disease of the Japanese eel, Anguilla japonica caused by Pleistophora anguillarum. TAKAHASHI and Egusa (1976) also reported on Glugea plecoglossi infection of ayu, Plecoglossus altivelis. Both infections were successfully controlled with fumagillin.

In myxosporeans, MolnAR et al. (1987) showed fumagillin- $0.1 \%$ diet was efficacious against the infection of the common carp, Cyprinus carpio with the renal sporogonic stage of Sphaerospora renicola, whereas its early stage in the swimbladder was not affected by fumagillin, nor were infections with Myxobolus cyprini in the muscle and Thelohanellus nikolskii in the fin of the common carp. Hedrick et al. (1988) demonstrated that oral administration of fumagillin protected chinook salmon, Oncorhynchus tshawytscha, from "PKD" (proliferative kidney disease caused by the myxosporean "PKX"). SzeKely et al. (1988) also showed fumagillin prevented the development of Myxidium giardi in the kidney of the European eel, Anguilla anguilla. Murakami (1980) reported oral administration of fumagillin $(2.5 \mathrm{mg} /$ fish $-\mathrm{kg} /$ day $)$ for 10 days in late April protected cultured yamame, Oncorhynchus masou and amago, $O$. rhodurus, from "sleeping disease" caused by Myxobolus sp. infection in the nervous tissue.

Toltrazuril (1,3,5 symmetrical triazinone), which has been found to be anticoccidial drug in poultry (MEHLHORN et al., 1984, HABERKORN and Stoltefuss, 1987), was reported to be also effective against various fish parasite infections; cilia tes, Ichthyophthirius multifiliis, Trichodina spp., Apiosoma spp.-MeHLHORn et al. (1988), Schmahl et al. (1989a), monogeneans, 
Dactylogyrus spp., Pseudodactylogylus spp., Gyrodactylus arcuatus-SCHMAHL and MEHLHORN (1988), the microsporean, Glugea anolomaSchmahl and MehlHorn (1989), and the myxosporean, Myxobolus sp.-SchmaHL et al. (1989b).

Kidney enlargement disease (KED) of goldfish, Carassius auratus, is caused by the myxosporean Hoferellus carassii, a common parasite in goldfish (AHMED, 1973, 1974, Molnar et al., 1989, Yokoyama et al., 1990), but therapy against KED has not been known. We therefore examined light and electron microscopically efficacy of fumagillin and toltrazuril to goldfish naturally infected with $H$. carassii, and discussed the mode of action by the drugs and the possibility for their practical use.

\section{Materials and Methods}

\section{Fish}

Several trials of treatment were made depending on the different developmental stages of the parasite.

Experiment 1 was designed for treatment of goldfish infected with an early developmental stage of Hoferellus carassii. In September 1989, goldfish were obtained from a fish farm in Tokyo, where the occurrence of KED were known every year. They were naturally infected with $H$. carassii, without showing the external symptoms (prevalence of infection $40 \%$, average body weight $1.3 \mathrm{~g}$ ).

Experiment 2 was carried out on fish with more advanced stages of the parasite. Goldfish already presenting gross symptoms of KED were collected from several goldfish farms in Tokyo, Saitama, and Aichi Prefectures (average body weight $2.8 \mathrm{~g}$ ).

Both experiments were performed in a 50 ! aquarium with parasite-free water at ambient temperature.

\section{Medicated Diets}

Fish were fed daily on commercial food containing the chemicals at 3 to $4 \%$ body weight per day.

Fumagillin, in the form of dodecylamine salt, was mixed at a dose of $0.1 \%$ or $1.0 \%$ in the feed $(=40$ or $400 \mu \mathrm{g} / \mathrm{g} \cdot$ fish $/$ day $)$.
Toltrazuril, a vailable in a $2.5 \%$ water soluble formulation (BAYER, Vi9142), was medicated at $0.7 \%$ or $7.0 \%$ in the feed (=7 or $70 \mu \mathrm{g} / \mathrm{g} \cdot \mathrm{fish} /$ day). The same food were used as a control diet without containing drug.

In Experiment 1, fish were administered the medicated diets from 27 September to 1 November. Subsequently, all the fish were fed the control diet until 15 December. Ambient temperature fluctuated from 15 to $20^{\circ} \mathrm{C}$ during the period.

Experiment 2 was performed twice in November and January, respectively. In November, goldfish with a gross sign of KED were divided into two groups, given fumagillin $0.1 \%$ and $1.0 \%$ diet, respectively, for 2 weeks. Ambient temperature ranged from 10 to $17^{\circ} \mathrm{C}$. In January, medicated diet containing 1.0\% fumagillin was used. Since fish lost the appetite with lowering water temperature (7 to $10^{\circ} \mathrm{C}$ ), it was subsequently raised to $13-16^{\circ} \mathrm{C}$ on 28 December. Fish were treated orally with fumagillin for 1 week from 3 January.

\section{Detection of the Parasite and Evaluation of Ef- ficacy of the Drugs}

In Experiment 1, the presence of the parasite and severity of KED was examined on 1 November (one month after the commencement of the experiment) and on 15 December (after 2.5 months). The prevalence of infection was determined by the presence of trophozoites in the kidney smear preparation. The degree of KED was categorized into "fish with a sign of KED", in which a gross sign of the infection was noted only after dissection, and "fish with a severe sign of KED", in which fish exhibited an externally visible sign of abdominal distention.

In Experiment 2, three to five fish were dissected 3 days, 1 week or 2 weeks after the commencement of the experiment, but untreated fish were monitered monthly from November to April. Kidney smear preparations were stained with MAY-GIEMSA.

The kidney was also used for light and electron microscopical observations according to the method of Yokoy ama et al. (1990). 


\begin{tabular}{|c|c|c|c|c|c|c|c|}
\hline \multirow[b]{2}{*}{0} & \multirow[b]{2}{*}{10} & \multicolumn{4}{|c|}{ Prevalence } & \multicolumn{2}{|c|}{$\left(\begin{array}{ll}8\end{array}\right)$} \\
\hline & & 20 & 30 & 40 & 50 & 60 & 70 \\
\hline
\end{tabular}
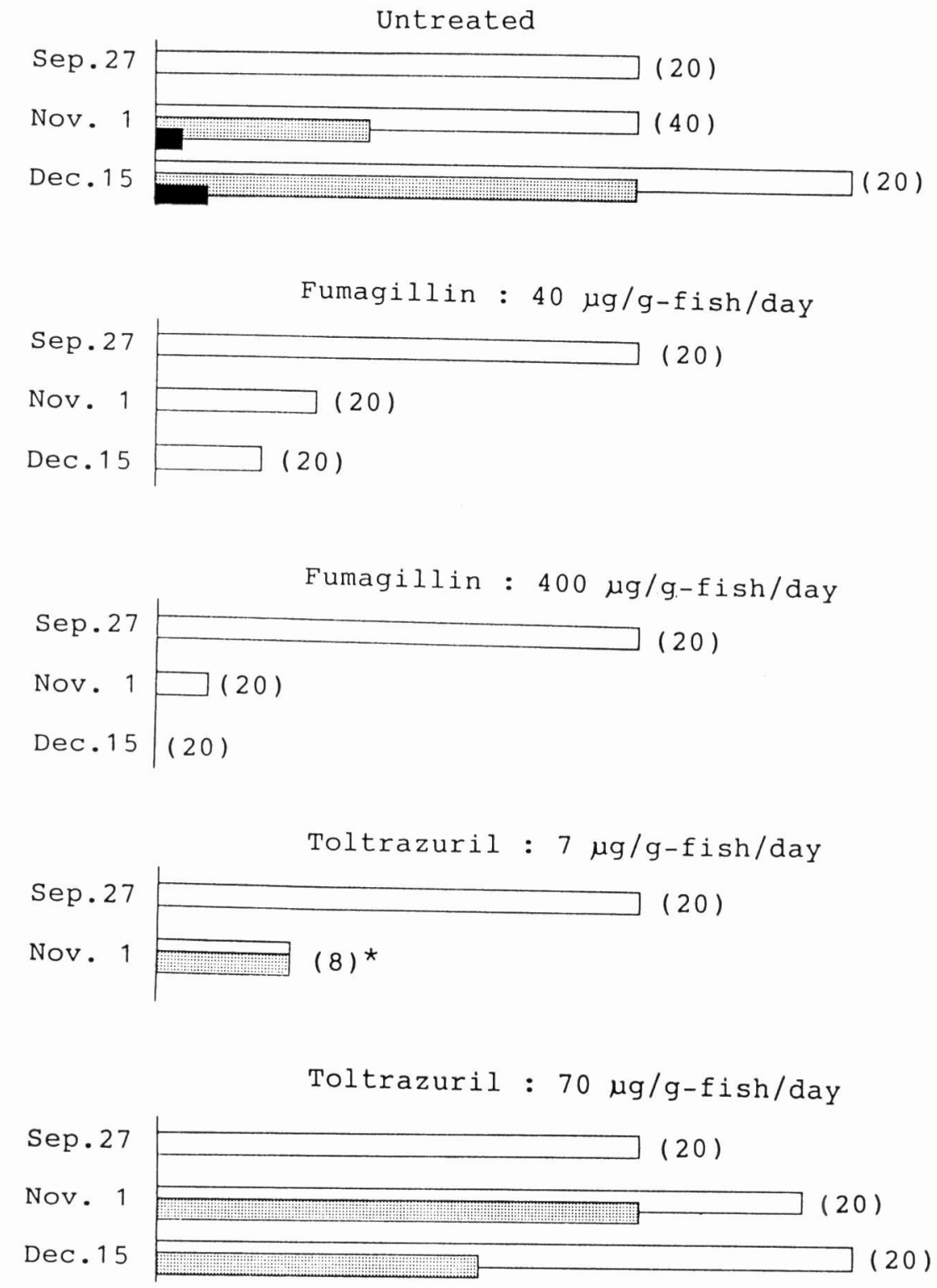

Fig. 1. Efficacy of fumagillin and toltrazuril against kidney enlargement disease (KED) of naturally infected goldfish. White, dotted and black bars represent the prevalence of infection, percentage of goldfish with a sign of KED, and percentage of goldfish with a severe sign of KED, respectively. Figures in parenthesis indicate the number of fish examined. Medicated diets were orally administered from Sep. 27 to Nov. 1. All fish were subsequently fed the control diet. *: The fish were accidentally lost. 


\section{Results}

\section{Experiment $I$}

In goldfish administered fumagillin $0.1 \%$ and $1.0 \%$ diets, the prevalence of infection was significantly decreased, and the fish never developed the symptoms of KED (Fig. 1). The number of trophozoites drastically decreased, and never increased after the treatment had stopped.

In contrast, the prevalence in untreated fish gradually increased up to $65 \%$ in December. Moreover, KED developed in $45 \% \mathrm{fish}$, of which $5 \%$ fish were severely affected. But the increase of the infection rate was thought to be owing to the increase of the detection rate associated with proliferation of the parasite.

In goldfish treated with toltrazuril, KED developed, and no significant difference from un- treated fish was observed.

\section{Experiment 2}

In fish treated with fumagillin in November, smear preparations showed the cytoplasm of trophozoites was poorly stained; secondary cells were shrunk and degenerated after 3 days of medication (Fig. 2).

In histological sections, both parasites and host cells were degenerated, and released into the lumen (Fig. 3). As a result, only the basement membrane remained in the tubule (Fig. 4). Electromicroscopy also showed irretrievable damages of intracellular trophozoites. Vacuolization in the parasite was distinct, the secondary cell was drastically shrunk, and mitochondria disappeared (Fig. 7). Moreover, host epithelial cells were also affected; its karyoplasm was lyzed, thus infected cells were dis-
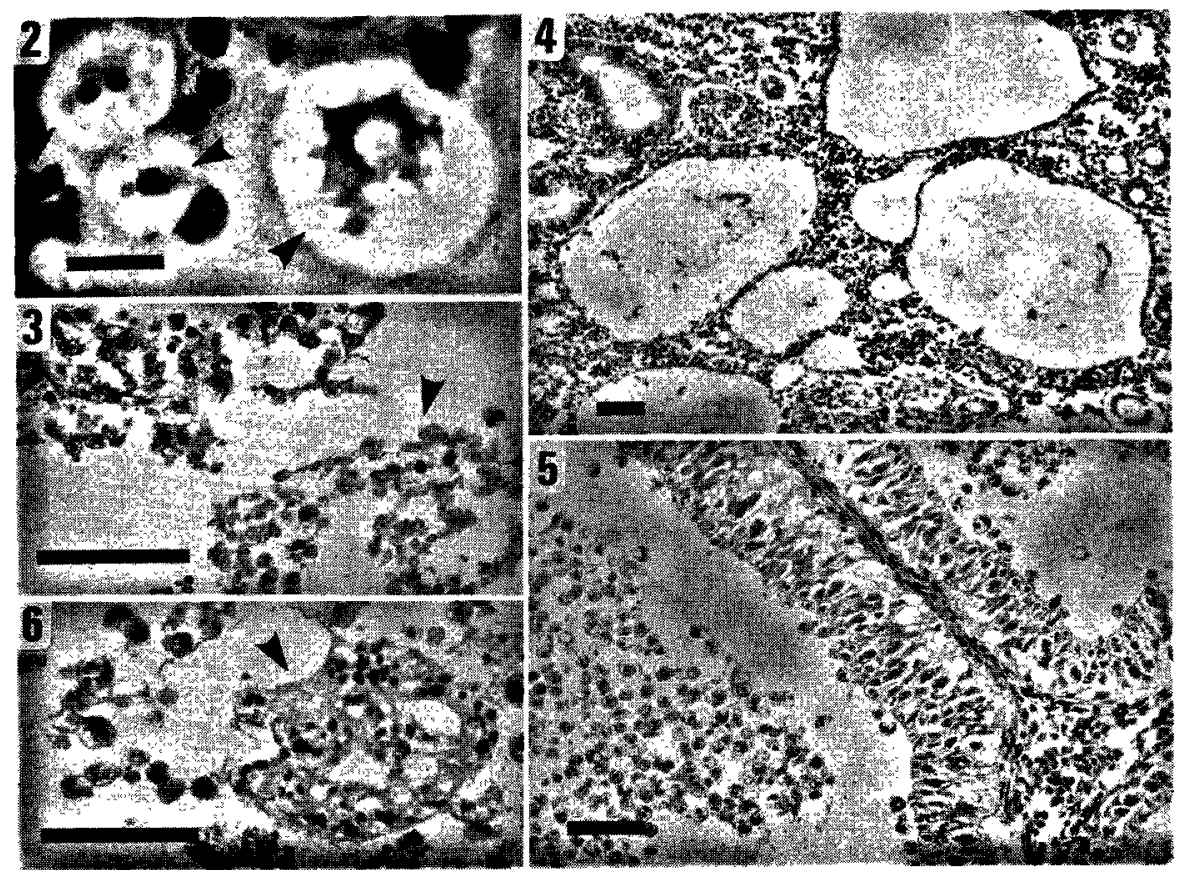

Fig. 2. Degenerated trophozoites (arrows) at 3 days after fumagillin treatment. Smear preparation, May-Giemsa stain. Scale: $10 \mu \mathrm{m}$.

Figs. 3 and 4. An infected tubule after fumagillin treatment in November. Histological section, haematoxylin-eosin stain. 3, Dead trophozoites and cellular debris (arrow) released into the lumen. 4. Tubule which lost infected epithelial cells, leaving only the basement membrane. Scale: $50 \mu \mathrm{m}$.

Figs. 5 and 6. An infected tubule after fumagillin treatment in January. Histological section, haematoxylin-eosin stain. 5. Tubule filled with fluid of degenerated parasites and host cells in the lumen. 6. Damaged large plasmodium (arrow) in the lumen. Scale: $50 \mu \mathrm{m}$. 

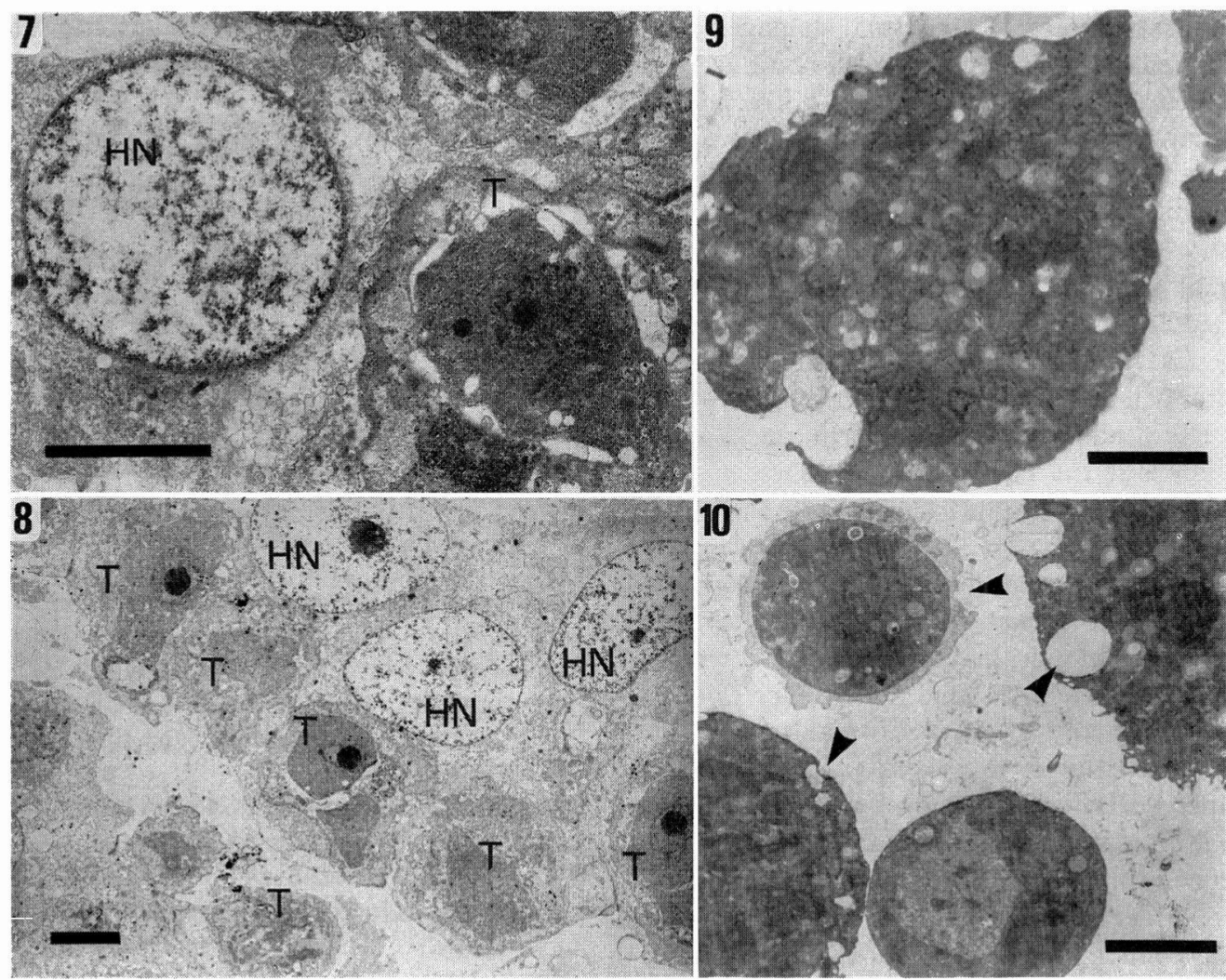

Figs. 7-10. Transmission electron micrographs. 7. Affected intracellular trophozoite. Note the shrinkage of secondary cell. 8. Dead host cells with lysed karyoplasm and dead trophozoites in the lumen at 2 weeks after fumagillin treatment in November. 9. Dying large trophozoite in the lumen. 10. Degenerated plasmodia in the lumen. Note the damages (arrow) in the outer surface of the cells and disappearance of the primary cell. $\mathrm{HN}$ : nucleus of host epithelial cell, T: trophozoite. Scale: $5 \mu \mathrm{m}$.

integrated and fell off into the lumen with dead parasites (Fig. 8). These alterations were observed after 3 to 7 days of treatment.

In the experiments in January, when parasites were already at intraluminar stages, fumagillin was also effective. The lumen of the infected tubule was filled with fluid of destroyed host cells and parasites (Figs. 5 \& 6). Damaged plasmodia completely lost the envelope cell, which was destroyed at the periphery of the parasite (Figs. $9 \& 10$ ). Finally, the tubule lost all the infected epithelia.

However, those alterations were never observed in untreated fish.

\section{Discussion}

This study indicates that fumagillin is effective against KED. Destructions of early intracellular trophozoites and more developed plasmodia of $H$. carassii by fumagillin treatment were observed with light and electron microscopy .

The mechanism of the action of fumagillin has not been elucidated. In microsporeans, Hartwig and Przelecka (1971) examined the mechanism cytochemically; it suppressed DNA synthesis of Nosema apis, whereas, JARONSKI (1972) reported RNA synthesis inhibition of Octosporea muscaedomesticae by fumagillin. In this study, since the development of parasites was never observed 1.5 month after the treat- 
ment (Experiment 1), and fatal damages were confirmed in microscopical observations (Experiment 2), fumagillin thus has hoferellocidal action rather than hoferellostatic action.

It is considered that dosage of the drug and the administration period depend on the intensity of infection. Infected but externally normal fish in October were completely prevented from developing KED with fumagillin $0.1 \%$ or $1.0 \%$ treatment for one month, whereas, in fish with a gross sign of KED, $1.0 \%$ fumagillin administration for two weeks could not improve the condition of KED.

Toxity of fumagillin to fish was indicated by Sitja and Alvarez (1989)*, who noticed that fumagillin-treated sea bass, Dicentrarchus labrax infected with Sphaerospora testicularis showed abnormal behavior, loss of appetite and weight, and symptoms of anemia. However, we did not observe any of the abnormalities.

In this study, toltrazuril was ineffective against KED, but the causes may possibly lie in the method of administration, or the difference in the site of the action. According to Schmahl et al. (1989b), Myxobolus sp. infection in the gill connective tissue of the bream, $\mathrm{Abra}$ mis brama, developmental stages of the parasite were severely affected, after bathing the fish in water with $10 \mu \mathrm{g}$ toltrazuril $/ \mathrm{ml}$.

Although our results may be applied to other myxosporean diseases, the method should be respectively considered depending on the process of development and the site of infection.

We can conclude that the antibiotic fumagillin has hoferellocidal action, and oral administration of fumagillin at $0.1 \%$ dose for one month, before development of KED, is the most effective.

\section{Acknowledgements}

The authors wish to thank Takeda Chemical Industries, Ltd., and Bayer Japan Ltd., for their offers of the chemicals.

\section{References}

Ahmed, A. T. A. (1973): Morphology and life histo-

* Sitja-Bobadilla, A. and P. Alvarez-Pellitero (1989): Int. Conf. Eur. Ass. Fish Pathol. 24-28 Sep., 1989, Spain, p. 195. ry of Mitraspora cyprini FuנITA, parasitic in the kidney of goldfish. Japan. J. Med. Sci. Biol., 26, 87-101.

Ahmed, A. T. A. (1974): Kidney enlargement disease of gold fish in Japan. Japan. J. Zool., 17, 37-65.

BaILY, L. (1953): The effect of fumagillin upon Nosema apis (Zander). Nature, 171, 212-213.

Haberkorn, A. and J. Stoltefuss (1987): Studies on the activity spectrum of toltrazuril, a new anticoccidial agent. Vet. Med. Rev., 1, 22-32.

Hartwig, A. and A. Przelecka (1971): Nucleic acids in intestine of Apis mellifica infected with Nosema apis and treated with fumagillin DCH; Cytochemical and autoradiographic studies. J. Invert. Pathol., 18, 331-336.

Hedrick, R. P., J. M. Groff, P. Foley and T. MCDowell (1988): Oral administration of fumagillin DCH protects chinook salmon Oncorhynchus tshawytscha from experimentally-induced proliferative kidney disease. Dis. aquat. Org., 4, 165-168.

JARONSKI, S. T. (1972): Cytochemical evidence for RNA synthesis inhibition by fumagillin. J. Antibiotics, 25, 327-331.

Kano, T., T. Okauchi and H. Fukui (1982): Studies on Pleistophora infection in eel, Anguilla japonicaII. Preliminary tests for application of fumagillin. Fish Pathol., 17, 107-114. (In Japanese).

Katznelson, H. and C. A. Jamieson (1952): Control of Nosema disease of honey bees with fumagillin. Science, 115, 70-71.

Mehlhorn, H., G. Ortmann-Falkenstein and A. HABERKORN (1984): The effects of sym. triazinones on developmental stages of Eimeria tenella, E. maxima and $E$. acervulina: a light and electron microscopical study. Z. Parasitenkd., 70, 173-182.

Mehlhorn, H., G. SChmahl and A. HaberkoRN (1988): Toltrazuril effective against a broad spectrum of protozoan parasites. Parasitol. Res., 75, 64-66.

Molnar, K., F. Baska and C. Szekely (1987): Fumagillin, an efficacious drug against renal sphaerosporosis of the common carp Cyprinus carpio. Dis. aquat. Org., 2, 187-190.

Molnar, K., T. Fischer-Scherl, F. Baska and R. W. Hoffmann (1989): Hoferellosis in goldfish Carassius auratus and gibel carp Carassius auratus gibelio. Dis. aquat. Org., 7, 89-95.

MuRAKami, Y. (1980): Studies on a sleeping disease (provisional name) of cultured yamame and amago-VIII. Timing of treatment, the dose of administration and efficacy of fumagillin. Annu. Rep. Freshwater Fish. Exp. St. Hiroshima Pref. Fiscal 1979, pp. 34-35. (In Japanese.)

Schmahl, G. and H. Mehlhorn (1988): Treatment of fish parasites 4 . Effects of sym. triazinone 
(toltrazuril) on Monogenea. Parasitol. Res., 75, 132 143.

Schmahl, G. and H. Mehlhorn (1989): Treatment of fish parasites 6 . Effects of sym. triazinone (toltrazuril) on developmental stages of Glugea anomala Moniez, 1887 (Microsporidia). A light and electron microscopic study. Eur. J. Protistol., 24, 252-259.

Schmahl, G., H. Mehlhorn and H. TARASchewski (1989a): Treatment of fish parasites 5. The effects of sym. triazinone (toltrazuril) on skin parasitic Ciliophora (Ichthyophthirius multifiliis FOUQUET 1876, Glossatella amoebea Grenfell, 1884, and Trichodina sp. Ehrenberg, 1831). Eur. J. Protistol., 24, 152-161.

Schmahl, G., H. Mehlhorn and H. TARASCHewSKI (1989b): Treatment of fish parasites 7. Effects of sym. triazinone (toltrazuril) on developmental stages of Myxobolus sp. Bütschli, 1882 (Myxosporea, Myxozoa): A light and electron microscopic study. Eur. J. Protistol., 25, 26-32.

Szekely, C., K. Molnar and F. Baska (1988): Efficacy of fumagillin against Myxidium giardi Cepede, 1906 infection of the European eel (Anguilla anguilla): New observations on myxidiosis of imported glass eels. Acta. Vet. Hung., 36, 239-246.

TAKAhAShi, S. and S. Egusa (1976): Studies on Glugea infection of the ayu, Plecoglossus altivelis II. On the prevention and treatment-(1) Fumagillin efficacy as a treatment. Fish Pathol., 11, 83-88. (In Japanese.)

Yokoyama, H., K. Ogawa and H. WaKabayashi (1990): Light and electron microscopic studies on the development of Hoferellus carassii (Myxosporea), the causative organism of kidney enlargement diseace of goldfish. Fish Pathol., 25, 149-156. 